\title{
Is there a gold standard in the treatment of acid-mediated ulcer diseases?
}

\author{
ABR THOMSON, MD, PHD, FRCPC, FACP, FRS, FACG
}

\begin{abstract}
ABR THOMSON. Is there a gold standard in the treatment of acid-mediated ulcer diseases? Can J Gastroenterol 1993;7(5):444-448. It is possible to achieve faster healing of duodenal ulcer disease, gastric ulcer disease and gastroesophageal reflux disease (GERD) with a proton pump inhibitor compared with an $\mathrm{H}_{2}$ antagonist. Higher rates of healing of duodenal ulcer disease may be achieved with a proton pump inhibitor rather than an $\mathrm{H}_{2}$ antagonist, especially when considering those individuals who have failed to heal after eight weeks of standard doses of $\mathrm{H}_{2}$ antagonist. It remains to be established whether the proton pump inhibitors are 'stronger' than $\mathrm{H}_{2}$ antagonists for the management of patients with GI bleeding, NSAID damage or $\mathrm{H}$ pylori, but it is likely that some combination of acid reduction in association with bismuth and one or more antibiotics may be necessary to achieve this result. Then the discussion will be less on what represents optimal maintenance therapy, and more on what represents the best form of therapy for healing the acute lesion, eradicating $\mathrm{H}$ pylori and preventing recurrence of disease.
\end{abstract}

Key Words: Duodenal ulcer, Gastroesophageal reflux disease, Gastric ulcer, $\mathrm{H}_{2}$ antagonists, Helicobacter pylori, Proton pump inhibitor

\section{$\mathrm{Y}$ a-t-il une norme en matière de traitement des maladies ulcéreuses liées à l'acidité?}

RÉSUMÉ: Il est possible d'arriver à une cicatrisation plus rapide de l'ulcère duodénal, de l'ulcère d'estomac et du reflux gastro-oesophagien avec l'inhibiteur de la pompe à protons, en comparaison avec un anti- $\mathrm{H}_{2}$. Des taux de cicatrisation de l'ulcère duodénal plus élevés sont atteints avec un inhibiteur de la pompe à protons qu'avec un anti- $\mathrm{H}_{2}$, particulièrement si l'on songe aux individus chez qui la cicatrisation ne s'est pas produite après une thérapeutique de huit semaines avec des doses standard d'anti- $\mathrm{H}_{2}$. Il reste à établir si l'inhibiteur de la pompe à protons est plus puissant que les anti- $\mathrm{H}_{2}$ dans le traitement de l'hémorragie digestive, des lésions attribuables aux AINS ou à $H$ pylori, mais il est probable qu'une combinaison d'agents suppresseurs d'acide et de bismuth, associée à un antibiotique ou plus, pourrait être nécessaire pour parvenir à ce résultat. La discussion portera done moins sur le traitement d'entretien optimum, et davantage sur la meilleure thérapeutique pour faire cicatriser les lésions aiguës, pour éliminer $\mathrm{H}$ pylori et prévenir la maladie.

Nutrition and Metabolism Rescarch Group, Department of Medicine. Unitersity of Alberta, Edmontom. Alberta

Comrespondence: Dr ABR Thomson, 519 Robert Newton Research Building, University of Alberta, Edmonton, Alberta T66 2C:2. Telephome (403) 492-6490, Fax (403) 492-7964
I MPORTANT ADVANCES CONTINUETO be accomplished in the management of patients with acid-pepsin diseases. These include the role of Helicobacter pylori in the pathogenesis of peptic ulcer disease, a cost-effective approach to the patient with gastroesophageal reflux disease (GERD), consideration of the importance of maintenance therapy, and consideration of the pros and cons of the prophylaxis and management of nonsteroidal anti-inflammatory drug (NSAID) gastroenteropathy.

To answer the question, 'Is there a new gold standard for the treatment of peptic disorders?' we first need to consider the science of managing patients with peptic ulcer disease, and address a number of other important questions. What is happening to peptic ulcer disease? What causes peptic ulcer disease? How much acid suppression is needed to heal peptic ulcer disease? When should acid be inhibited? Are $\mathrm{H}_{2}$ antagonists the best treatment for peptic ulcer disease? Why use maintenance therapy? Is maintenance therapy safe? Perhaps we need to add an additional question: "Can peptic ulcer disease be cured?

\footnotetext{
WHAT IS HAPPENING TO PEPTIC ULCER DISEASE?

The number of patients admitted to hospital for peptic ulcer disease has declined dramatically, as has the number of individuals requiring surgery for their
} 
gastric or duodenal ulcer. However, the prevalence of peptic ulcer disease in males has remained relatively constant in the last generation, and the prevalence in females has increased remarkably, to the point now that the numbers of men and women with peptic disorders are approximately similar. The shift, therefore, has been from in-patient to out-patient practice, and away from the large number of individuals who were refractory to the relatively ineffective therapy available in the precimetidine era. Patients with peptic ulcer disease do not usually need hospitalization now except for complications. Effective therapy is in the hands of family physicians, who are able to take very good care of these patients who, in the past, needed hospitalization and surgery.

\section{WHAT CAUSES PEPTIC ULCER DISEASE?}

We are really not much closer to answering the question of what causes peptic ulcer disease now than we were 15 years ago. One might wax eloquently about an imbalance between the aggressive acid-peptic activity and the defensive mucosal protection factors important in the pathogenesis of GERD, duodenal ulcer disease and gastric ulcer disease. Clearly, acid is of some importance in the pathogenesis of these disorders, and acid secretion can be measured clinically and can be demonstrated to be abnormal in some patients with duodenal ulcer disease. For example, with increasing doses of pentagastrin there is increasing acid output; this linear relationship is shifted to the left in patients with duodenal ulcer disease, suggesting increased sensitivity of the parietal cell to this stimulation (1). Of course pentagastrin is not a natural stimulant, so we need to address the consideration of the effect of food on acid secretion in normals and in patients with duodenal ulcer disease. In response to a standard meal, there is a modest increase in acid secretion rate to approximately $30 \mathrm{mEq} / \mathrm{h}$ in normal volunteers compared with values of over $60 \mathrm{mEq} / \mathrm{h}$ in patients with duodenal ulcer disease (2).

In these studies, the acid concentra- tion was measured in the gastric lumen. Gastric mucosal cells secrete bicarbonate, which gives rise to an alkaline microclimate adjacent to the gastric membrane. Whereas the $\mathrm{pH}$ in the gastric lumen may have an acidic value of $\mathrm{pH} 2$, the $\mathrm{pH}$ of the gastric membrane is more alkaline, approaching $\mathrm{pH} 7$. While this secretion of bicarbonate is capable of neutralizing only approximately $5 \%$ of the secreted hydrochloric acid, this is a sufficient amount to establish and maintain this alkaline microclimate. In patients with duodenal ulcer disease there may be impairment of the alkaline microclimate so that the $\mathrm{pH}$ at the gastric or duodenal membrane may be more acidic (3). Indeed, in normal individuals, in response to perfusion of the duodenum with hydrochloric acid, there is a brisk increase in the output of bicarbonate in the proximal duodenum, but this bicarbonate secretion is markedly impaired in patients with duodenal ulcer disease (1). There is also impairment in the food-stimulated secretion of prostaglandin $\mathrm{E}_{2}$ from the duodenal mucosa in patients with duodenal ulcer disease (1), which may be partly responsible for the impaired output of bicarbonate and the reduced alkaline microclimate. Thus, in some individuals with peptic disorders, there are abnormalities in acid secretion, in the alkaline microenvironment, and the secretion of bicarbonate and prostaglandins.

Kurata $(4,5)$ has formulated a simple model of the pathogenesis of peptic ulcer disease in which the end-product of excessive aggressive factors (acid and pepsin) and impaired mucosal defense lead to the development of an ulcer. Rarely, an acid hypersecretory state may occur, such as in patients with the Zollinger-Ellison syndrome. The aggressive and defensive factors may also be abnormal in patients with a family history of peptic ulcer disease or as a result of smoking. Other environmental contributors to the development of an ulcer include NSAIDs and H pylori.

Much has been written and spoken about the role of $H$ pylori, and clearly this is important for the development of chronic nonspecific gastritis. Most, if not all, patients wirh duodenal ulcer disease and many with gastric ulcer disease have $H$ pylori, and the relapse rates of duodenal ulcer disease are higher in those individuals with persistent $\mathrm{H}$ pylori than in those in whom $H$ pylori is eradicated. Indeed, the higher relapse rates in duodenal ulcer disease patients who continue to smoke are similar to nonsmokers when $H$ pylori is cleared (6).

\section{HOW MUCH ACID SUPPRESSION IS NEEDED TO HEAL PEPTIC ULCER DISEASE?}

If we accept that acid has some role to play in the pathogenesis of peptic ulcer disease and its treatment, then we can turn our attention to this important question: 'How much acid suppression is needed to heal peptic ulcer disease?' We recognize the important studies of Hunt's group, in which it was demonstrated that there is a linear relationship between the suppression of $24 \mathrm{~h}$ acidity and the healing rate of duodenal ulcers at four weeks. With greater acid inhibition, there are higher rates of ulcer healing. By extrapolating this linear relationship to zero acid suppression, one would predict an ulcer healing rate of approximately $30 \%$, a healing rate which may be achieved by using placebo rather than by suppressing acid output. This suggests the possibility that factors other than acid-pepsin are important in the pathogenesis and healing of duodenal ulcer disease. The relationship between suppression of acidity and ulcer healing also predicts that with $100 \%$ suppression of acid, virtually all patients with duodenal ulcer disease will heal.

This same group of researchers has identified a $\mathrm{pH}$ of 3.0 as the threshold value above which the intragastric $\mathrm{pH}$ must be reduced for ulcers to heal (7). For example, if one wished to achieve $90 \%$ ulcer healing in four weeks, then the intragastric fluid would need to be maintained above $\mathrm{pH} 3.0$ for approximately $18 \mathrm{~h}$ per day. More modest acid inhibition would be associated with lower rates of ulcer healing, but higher rates of ulcer healing could be maintained not necessarily by increasing acid suppression, but by simply treating the patient for longer. The concepts 
that ulcer healing requires the $\mathrm{pH}$ to he increased above 3, and that it is not necessary to achieve $\mathrm{pH}$ values of 4,5 or 6 , are important. Furthermore, it is not just the degree of acid inhibition that is important, but also the duration of maintaining the acid above a critical level of $\mathrm{pH} 3$.

There used to be much concern about the identification of the optimal time of administering acid inhibition for the healing of peptic ulcer disease. While taking an $\mathrm{H}_{2}$ receptor antagonist may modestly reduce its acid inhibiting effect if it is consumed with a meal, it is no longer deemed to be critical whether an evening dose of an $\mathrm{H}_{2}$ antagonist is taken after supper or at bedtime. Indeed, with the potent proton pump inhibitors, it becomes less critical to identify an exact time of day for medication to be taken.

\section{ARE $\mathrm{H}_{2}$ ANTAGONISTS THE BEST TREATMENT FOR PEPTIC ULCER DISEASE?}

The answer to the question of whether $\mathrm{H}_{2}$ antagonists are the best treatment for peptic ulcer disease will depend on each physician's experience and reading of the literature. I would like to provide a perspective of the interpretation of the literature and a sharing of the experience of other investigators who have attempted to answer this question.

Peptic ulcer disease is a chronic illness for which a given medication is a treatment, not a cure. The patient's symptoms can be alleviated successfully by a variety of medications and the ulcer will heal in a high proportion of patients, but once therapy is stopped ulceration will usually recur. From a patient's perspective, he/she wishes to have improvement of their symptoms and ulcer healing so that there will be prevention of the development of serious complications. Perhaps an additional therapeutic goal will soon be available - the possibility of a cure for duodenal ulcer disease by eradication of Hpylori.

A group of distinguished Canadian gastroenterologists, surgeons and general practitioners met in Ottawa in January 1992 to develop a Canadian consensus for the management of patients with GERD (8). This document requires careful study and consideration, and will be the basis for discussion in the future and, of course, for future studies. In essence, the recommendations suggested that for patients who do not have danger symptoms, but simply have typical symptoms of GERD, initial treatment should be lifestyle modification and over-the-counter therapy. $\mathrm{Pa}$ tients will often do this on their own accord and if they have not, then the physician may institute this therapy. If there is no response to lifestyle modification and over-the-counter therapy, then an $\mathrm{H}_{2}$ antagonist or possibly a prokinetic agent is added. It is important for the patient to be followed-up in four to eight weeks, and if there is no response at that point to standard doses of $\mathrm{H}_{2}$ antagonist, then an endoscopy should be performed.

The purpose of the endoscopy is to determine whether the patient's symptoms are on the basis of erosive esophagitis. If the endoscopy is essentially normal, the patient can continue on lifestyle modification, over-thecounter therapies and standard doses of $\mathrm{H}_{2}$ antagonist used for a longer interval, or the use of higher doses of $\mathrm{H}_{2}$ antagonists. If there is erosive esophagitis, then the patient should be placed on a proton pump inhibitor for two to three months, and maintained on a proton pump inhibitor if there is concern about the recurrence of peptic esophagitis.

It needs to be stressed that this was an important consensus because it facilitated the development of an algorithm that is useful for a simplified approach to patients with GERD, and may provide cost-saving for the health care system in Canada. I wish to point out a number of additional considerations. Cleator and colleagues (unpublished data) undertook a single-blind, randomized, parallel group study of 1035 patients treated with omeprazole $20 \mathrm{mg}$ daily, and 495 patients treated with ranitidine $300 \mathrm{mg}$ daily for duodenal ulcer disease ( 577 patients) or for GERD (904 patients). Symptomatic improvement was superior with omeprazole compared with ranitidine, particularly for the symptoms of (GERD, both during the daytime and at night, and at two and four weeks. This confirmed the results of superior symptomatic improvement with omeprazole compared with ranitidine, as described in a number of other comparative studies.

We need to carefully consider, therefore, why an equally safe and possibly equally expensive treatment (proton pump inhibitor versus $\mathrm{H}_{2}$ antagonist) should be withheld as initial therapy when the symptom control is so effective. Also, we need to remind ourselves that when patients with reflux esophagitis are treated with placebo, there is an extremely low natural rate of healing of the esophagitis. Esophagitis healing rates of $70 \%$ to $94 \%$ occur with omeprazole 20 to $40 \mathrm{mg}$ daily given for four to eight weeks (9). These healing rates are at least twice as high as those achieved with $\mathrm{H}_{2}$ antagonists. So again it has to be carefully considered what is the rationale for not using a proton pump inhibitor in a patient with symptoms of GERD when symptom relief and esophagitis healing are superior with such an agent. These points need to be carefully considered, debated, studied and applied to our individual practices.

There are several studies which showed a slightly higher four-week healing rate of gastric ulcer disease in patients treated with omeprazole $20 \mathrm{mg}$ daily compared with ranitidine $150 \mathrm{mg}$ bid, cimetidine $400 \mathrm{mg}$ bid or famotidine $20 \mathrm{mg}$ bid. The therapeutic gain is small, about $10 \%$ in favour of proton pump inhibitor compared with $\mathrm{H}_{2}$ antagonists. Interestingly, in patients with gastric ulcers who continue on NSAIDs, the ulcer healing rate is higher in patients taking omeprazole than in those taking ranitidine.

Poynard and Pignon (10) assessed the four-week healing rates of 11 drugs and placebo in the acute treatment of duodenal ulcer disease. Whether using an $\mathrm{H}_{2}$ antagonist, subcitrate bismuth, sulcrate, high dose antacids, enprostil (Syntex, California), pirenzepine or misoprostol, four-week healing rates of approximately $65 \%$ to $80 \%$ are achieved, in contrast to healing rates in excess of 90\% achieved with omeprazole. Thus, 
physicians and patients fortunately have many choices for treating acute duodenal ulcer disease.

But what happens to the proportion of patients who do not heal in four weeks? Many patients will be treated for longer and some will heal. However, there is the concept of 'resistant' or 'refractory' duodenal ulcer disease in which the ulcer has not healed after eight weeks of standard doses of $\mathrm{H}_{2}$ antagonist. Approximately 10\% to $15 \%$ of duodenal ulcer disease patients will be resistant to healing with an $\mathrm{H}_{2}$ antagonist. This concept needs to be reconsidered because with adequate doses of omeprazole given for sufficiently long, virtually all patients will heal their duodenal ulcer disease (11).

Lauritsen and colleagues (11) undertook a comparative study of omeprazole $20 \mathrm{mg}$ daily versus $40 \mathrm{mg}$ daily in 1004 duodenal ulcer disease patients. With omeprazole $20 \mathrm{mg}$ daily, the fourweek healing rate was $93.3 \%$ (429 of 460 patients) compared with $97.1 \%$ (465 of 479 patients) in patients treated with omeprazole $40 \mathrm{mg}$ daily. The eight-week healing rates were $96.7 \%$ and $99.8 \%$, respectively. What happened to the 16 patients treated with omeprazole for eight weeks who had not healed? When they were continued on omeprazole $40 \mathrm{mg}$ daily for an additional four or eight weeks they all healed. Thus, it is possible to achieve $100 \%$ healing of duodenal ulcer disease if omeprazole is continued sufficiently long. The only factor predicting duodenal ulcer disease healing rates at two weeks was the ulcer size; larger ulcers took longer to heal than smaller ulcers, and ulcers healed well even in patients continuing to take NSAIDs or smoke, or who had a long history of duodenal ulcer disease or were older.

\section{WHY USE MAINTENANCE THERAPY?}

Peptic ulcer disease is a recurrent disorder; patients with reflux esophagitis quickly recur after the esophagitis has healed (12), so that within six months of being off therapy, approximately $80 \%$ of patients initially healed on omeprazole or ranitidine will have recurrent esophagitis. If these patients are maintained on ranitidine $150 \mathrm{mg}$ bid, many will still recur over the next year, and the recurrence rates are much lower in patients maintained on omeprazole $20 \mathrm{mg}$ daily $(13,14)$. It is for this reason that the Canadian consensus group recommended that patients with erosive esophagitis be placed on maintenance therapy with proton pump inhibitors. For those physicians who remain hesitant to place patients long term on a proton pump inhibitor, it is reassuring to note that higher doses of ranitidine ( $300 \mathrm{mg}$ bid) may be useful maintenance therapy in GERD (15).

Both gastric ulcer and duodenal ulcer disease recur quickly once the patient is taken off therapy. For example, approximately $80 \%$ of patients will have a recurrence when off their therapy over the year after initial ulcer healing. If patients are maintained on cimetidine or ranitidine, the recurrence rates are lower. We do not yet have the results of a maintenance trial of over 900 patients placed on omeprazole $10 \mathrm{mg}$ daily, $20 \mathrm{mg}$ daily or ranitidine $150 \mathrm{mg}$ daily. This is an important and potentially classic study since it will demonstrate, in a large number of patients, whether ulcer recurrence can be maintained with higher levels of acid inhibition. These studies will also allow us to determine the long term safety of maintenance therapy with a proton pump inhibitor.

Why is there all this interest in the prevention of ulcer recurrence? Certainly for the quality of life of the patient with peptic ulcer disease, prevention of recurrence is important. About one-third of patients with a peptic ulcer have a lifetime risk of bleeding, and approximately $5 \%$ have a lifetime risk of a perforation. Once an ulcer, always an ulcer, and once a bleeding ulcer, always a bleeding ulcer - rebleeding occurs at a rate of approximately $33 \%$ at five years and $48 \%$ at 10 years, and the lifetime risk of reperforation is approximately 9\%. Penston and Wormsley (16) have demonstrated that the high cumulative rate of hemorrhage from recurrent duodenal ulcer disease when a patient is on no mainte- nance therapy is dramatically reduced with maintenance treatment.

\section{IS MAINTENANCE THERAPY SAFE?}

It is well appreciated and recognized that omeprazole and the $\mathrm{H}_{2}$ antagonists are very safe for short term use. In studies involving thousands of patients, serious adverse effects reported in comparative studies show an incidence of 0.7 to $1 \%$ for patients treated with ranitidine, cimetidine or omeprazole, and of $4.7 \%$ in patients treated with placebo (17). But the real question concerns the potential complications of long term medical therapy. An increase in serum gastrin concentration occurs with $\mathrm{H}_{2}$ antagonists and proton pump inhibitors, but the hypergastrinemia after proximal gastric vagotomy is even greater than with maintenance therapy with omeprazole. Regular surveillance of serum gastrin concentrations were undertaken in the maintenance study of omeprazole versus ranitidine in duodenal ulcer disease, and it will be of great interest to determine whether the median concentrations of serum gastrin increase and, more importantly, whether many of these values increase into the abnormal range. There is no evidence of an increased risk of gastric cancer in patients maintained on $\mathrm{H}_{2}$ antagonists or proton pump inhibitors, or in patients undergoing proximal gastric vagotomy. While some $\mathrm{H}_{2}$ antagonists and omeprazole influence drug metabolism, the effect is small and is usually not of major clinical significance. In the omeprazole duodenal ulcer disease maintenance study, gastric biopsies were taken at regular intervals during the one-year follow-up. It will he of great interest to learn whether there were any morphological changes occurring with ranitidine or omeprazole.

\section{CAN PEPTIC ULCER DISEASE BE CURED?}

This is a provocative and challenging question. At the present time the answer is 'a definite maybe'. There clearly is an association between $\mathrm{H}$ pylori and duodenal ulcer disease, but it is not yet clear what is the nature of the interaction between $\mathrm{H}$ pylori and $\mathrm{pH}$. 
In an important study by Graham and colleagues (18), patients were treated with either ranitidine alone or ranitidine $(150 \mathrm{mg}$ bid) plus triple therapy with hismuth subsalicylate (Pepto Bismol; Procter \& Gamble) five to eight tablets daily for two weeks, terracycline 2 g daily, plus metronidazole $750 \mathrm{mg}$ daily. Treatment was continued until the ulcer had healed or for 16 weeks. Endoscopies were performed at regular intervals for the next vear, while the patients were off therapy. For patients with duodenal ulcer or gastric ulcer disease treated with ranitidine alone, there was a high rate of recurrent ulceration. In contrast, for those patients treated with ranitidine plus triple therapy there was a very low rate of ulcer recurrence. The $H$ pvlori status was assessed by culture, biopsy or urea breath test, and no $H$ pylori-negative patient had an ulcer recurrence.

This raises the very important concept that if it is possible to eradicate H pylori, then it may be possible to 'almost cure' current duodenal ulcer

\section{REFERENCES}

1. Isenherg JK, Grossman M1, Maxwell V. Walsh JH. Increased sensitivity to stimulation of acid secretion by pentagastrin in deodenal uleer. J Clin lnvest 1975;55:330-7.

2. Fordtran IS. Walsh JH. Gistric acid secretion rate and buffer content of the stomach after eating. Results in normal subjects and in patients with duodenal ulcer. J Clin Invest 1973;52:645-7.

3. Quigley EMM, Turnberg LA. pH of the microclimate lining human gastric and dusdenal mucosa in vivo. Studies in control subjects and in duodenal uker patients. Gastroenterology 1987;92:1876-82.

4. Kurata JH. Ulcer epidemiology: An overview and proposed research framework. Gastroenterology 1989;96:569-80.

5. Kurata HI, Corboy ED, Current peptic uleer time trends: An epidemiologic profile. J Clin Gastronterol 1988:10:259-68.

6. Borody TJ, George LL, Brandl S, Andrews P, Jankiewicz E, Ostapowicz N. Simoking does not contribute to duodenal uleer relapse after Helicobacter pylori eradication. Am J Gastroenterol 1992;87:1390.3. and gastric ulcer disease. Much controversy exists around the selection of anti-H pylori therapy, he it triple therapy, ranitidine, bismuth compound plus one or more antibotics, or omeprazole plus amoxicillin. This is an important consideration because it may be a platinum rather than a gold standated in the future which we need to consider regarding eradication of $\mathrm{H}$ pylori.

\section{GOING FOR GOLD}

In 1885 Father Didon conned the Olympic motto 'Citius-Altius-Fortius', Faster-Higher-Braver, or SwifterHigher-Stronger. Certainly it is possible to achieve faster healing of duodenal ulcer disease, gastric ulcer disease and (IERD) with a proton pump inhibitor compared with an $\mathrm{H}_{2}$ antagonist. Higher rates of healing of duodenal ulcer disease may be achieved with a proton pump inhibitor rather than an $\mathrm{H}_{2}$ antagonist, especially when considering those individuals who have failed to heal after eight weeks of standard doses of $\mathrm{H}_{2}$ antagonist. It remains to be estab-

7. Burget DW, Chiverton SG, Hunt RH. Is there an optimal degree of acid suppression for healing of duodenal ulcers? Gastroenterolongy 1990;99:345-51.

8. Beck IT, Connon J, Lemire S, et al. Canadian consensus onference on the treatment of gastroesophageal reflux disease. Can J Gastroenterol 1992;6:277-89.

9. Thomson ABR. Medical treatment of reflux disease: Options and prisrities. Hepatogastroenterology 1992;39(Suppl 1):14-23.

10. Poynard T, Pignon JP. Acute treatment of dundenal ulcer. Analysis of 293 random clinical trials. New York: John Libbey and Sons, 1989.

11. Lauritsen K, Rutgersson K, Bolling E, et al, on behalf of an Internal Multicentre Study Group. Omeprazole 20 or $40 \mathrm{mg}$ daily for healing of duodenal ulcer? Gastroenterology 1992;102:A109.

12. Sandmark S. Carlsson R, Fausa O, Lundell L. Omeprazole or ranitidine in the treatment of reflux esophagitis. Scand I Gastronterol 1988;23:625-32.

13. Lundell GE, Westin IH, Sandmark S, et al. Omeprazole or high dose ranitidine in the treatment of patients lished whether the proton pump inhihitors are 'stronger' than $\mathrm{H}_{2}$ antagonists for the management of patients with Gi bleeding, NSAll damage or $H$ pylori, but it is likely that some combination of acid reduction in association with bismuth and one or more antibiotics may be necessary to achieve this result. Then, the discussion will be less on what represents optimal maintenance therapy, and more on what represents the hest form of therapy for healing the acute lesion, eradicating $H$ pylori and preventing recurrence of disease.

\section{SUMMARY}

I suggest to you that the very concept of a 'gold standard' needs to be re-examined. Paraphrasing a recent advertising slogan, I suggest that when we consider a gold standard, 'universal acceptance is the true value of gold!' Thus, the gold standard will be set by yourselves, by your acceptance of what works best for you and for your patients, and in that way you yourself will define your own gold standard.

with reflux esophagitis not responding to standard doses of $\mathrm{H}_{2}$-receptor antagonists, Gastroenteroligy 1989;96:A 310

14. Lunlell GE, Backman L, Ekstrom P, et al. Prevention of relapse of reflux esophagits after endoseopic healing: The efficacy and safety of omeprazole compared with ranitidine. Scand J Gistroenterol 1991:26:248.56.

15. Halvorsen L, Hazenhery RP, Hegarty J, et al. Prevention of relape in effect of two ranitidine desage regimens on the patients with reflux oesophagitis. Presented at the First United European Gastroenterology Week, Athens, Greece, 1992.

16. Penston J. Wormsley KG. Efficacy and safety of long-term maintenance therapy of dusedenal ulcers. Scand J Gastroenterol 1989;24:1145-52.

17. Solvell L. The elinical safery of omeprazole. Scand I Gastruenterol 1989;166(Suppl):106-10.

18. Graham D)Y, Lew (iM, Klem PD), et al. Effect of treatment of Helicobuter palori infection on the long-term recurrence of gastric or duodenal ulecr. A randomized controlled study. Ann Intern Med 1992:1 16:705-8. 


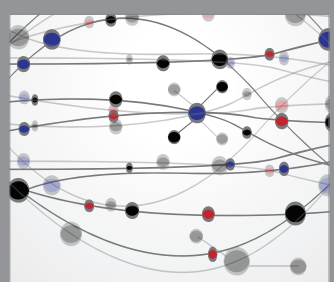

The Scientific World Journal
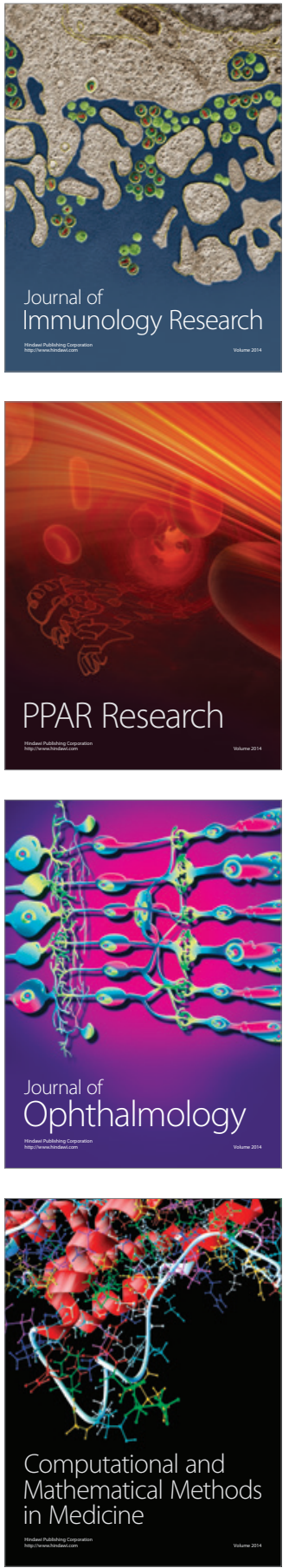

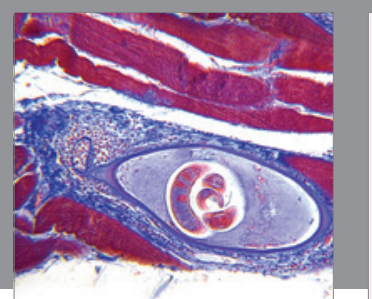

Gastroenterology Research and Practice

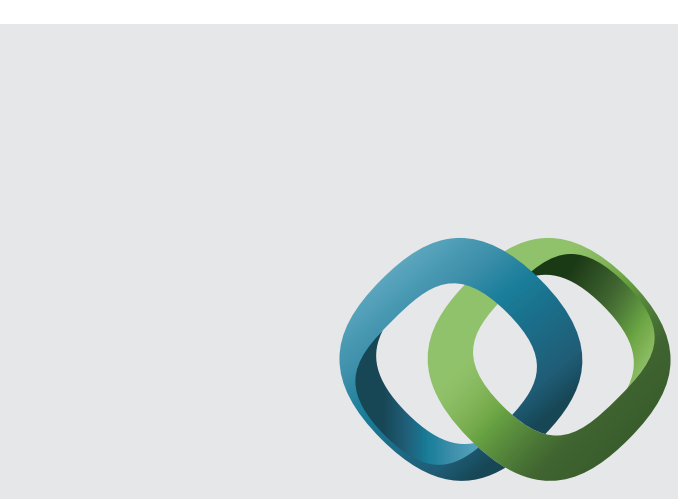

\section{Hindawi}

Submit your manuscripts at

http://www.hindawi.com
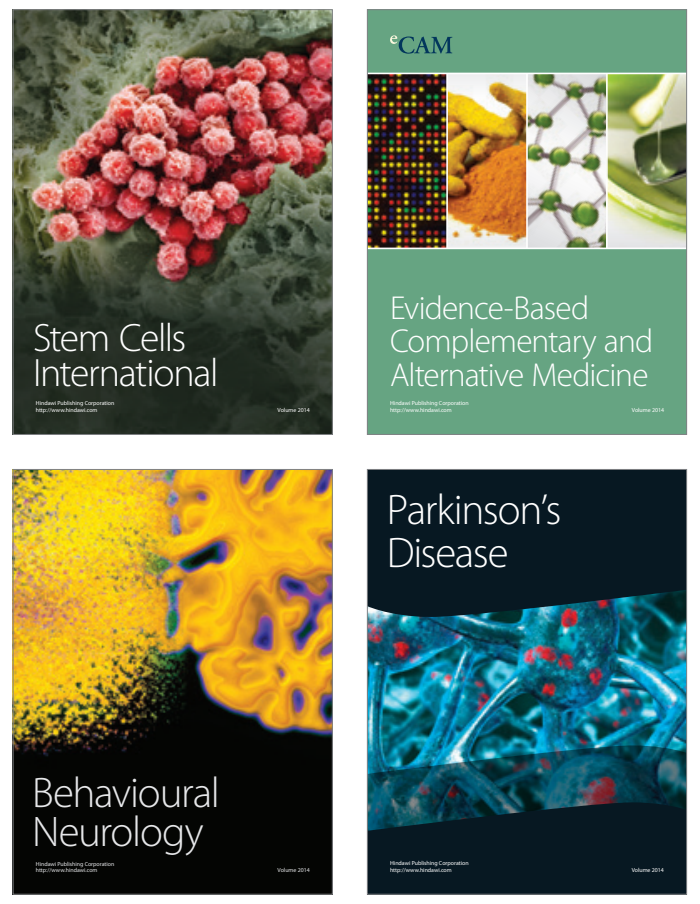
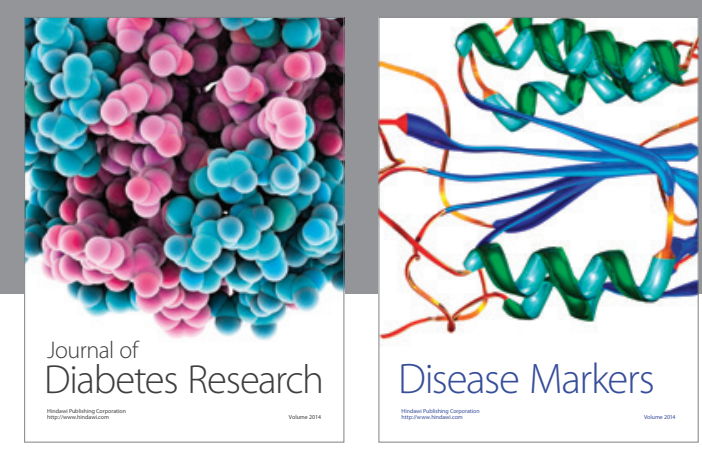

Disease Markers
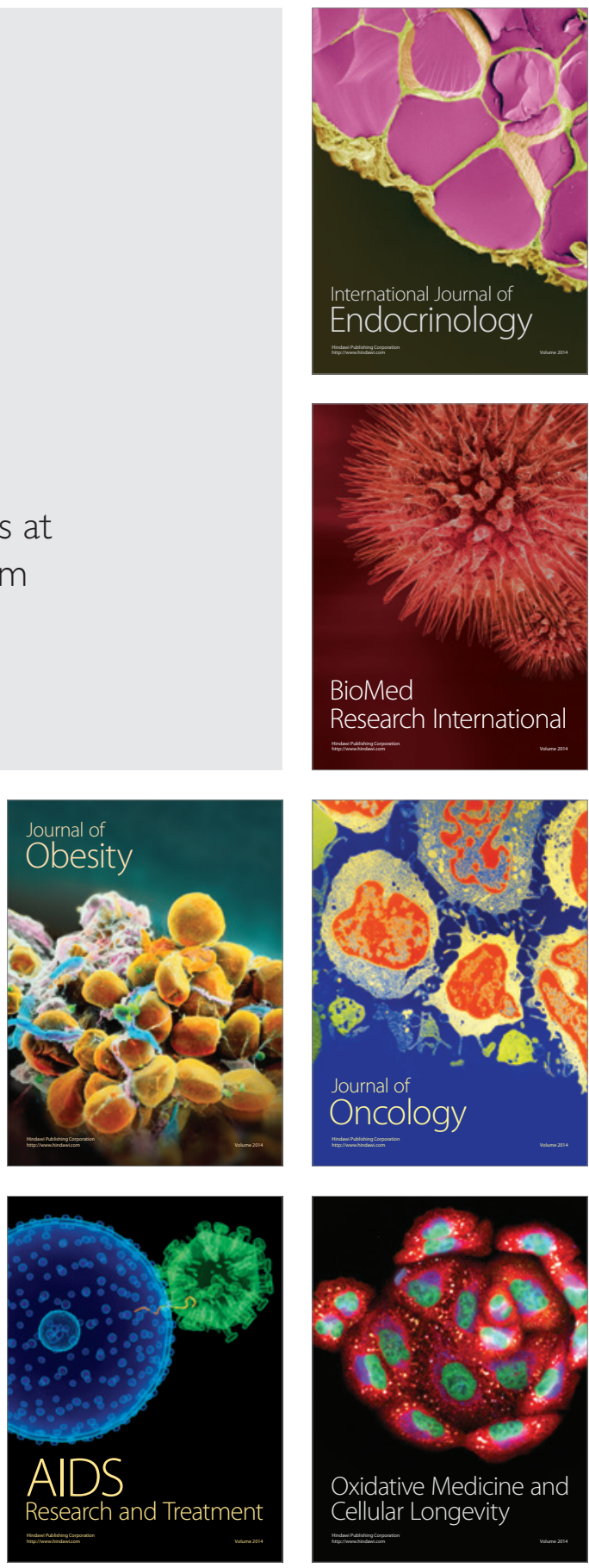